Natural Hazards and Earth System Sciences (2004) 4: 783-791

SRef-ID: 1684-9981/nhess/2004-4-783

European Geosciences Union

(C) 2004 Author(s). This work is licensed

under a Creative Commons License.

\title{
Analysis of different water-sediment flow processes in a mountain torrent
}

\author{
M. Arattano ${ }^{1}$ and L. Franzi ${ }^{2}$ \\ ${ }^{1}$ CNR-IRPI, Strada delle Cacce,73, 10135 Torino, Italy \\ ${ }^{2}$ Regione Piemonte, Corso Tortona, 12, 10183 Torino, Italy
}

Received: 6 April 2004 - Revised: 22 September 2004 - Accepted: 22 November 2004 - Published: 30 November 2004

Part of Special Issue "Monitoring and modeling of landslides and debris flows"

\begin{abstract}
Sediment - water flows occurring in mountain torrents may show a variety of regimes, ranging from water flows with transport of individual particles to massive transport of debris, as it occurs in case of debris flows. Sometimes it is possible, by means of accurate field investigations, to identify the kind of processes that took place in a torrent after the occurrence of an event. However this procedure cannot give indications regarding the development of the process in time. In fact, because of the frequent presence of different surges within the same event, the rheological characteristics of an event can be detected only when some recorded hydrographs or videos are available. For the same reason, since the rheological behaviour of the flow changes according to the solid concentration, the analysis of the materials deposited on the debris fan cannot directly give any information on the particular types of flow that took place: a possible alternation in time of different water sediment surges with different concentrations may have occurred, during the same event. The installation of ultrasonic gauges or videocameras along the torrent might give more information on this issue. To this regard, the analysis of a flow event which occurred in 2002 in the Moscardo torrent watershed, instrumented for debris flow monitoring, has been undertaken, studying the hydrographs recorded at two different ultrasonic gauges placed at a known distance along the torrent. An empirical flow resistance law has been applied analysing the values assumed by its parameters after calibration. The application of this law actually spans from debris flow and immature debris flow to bed load transport. Only field observations and surveys, together with ultrasonic data, may allow to clearly discriminate which type of flow really occurred. The analysis confirms that different water sediment surges alternated in time while the mathematical simulation of the flow compared with field observations revealed that the dynamic behaviour of the flow was different from that of previous debris flow events and might reflect,
\end{abstract}

Correspondence to: M. Arattano

(m.arattano@irpi.cnr.it) among the different types of possible rheological behaviors, a dilatant-type behavior typical of stony debris flows.

\section{Introduction}

In torrents prone to sediment transport, field evidence may suggest a variety of flow regimes, ranging from water flows with transport of individual particles to massive transport of debris, in the case of debris flows. Pierson (1986) describes some debris flows recorded at Mount St. Helen (State of Washington, USA) and notices that the debris flow front is generally followed by a progressively more diluted tail, characterized by the onset of turbulence. At times, diluted water-sediment surges are also observed, especially when the deposit of large boulders along the narrow torrent causes a temporary damming of the channel and subsequent overtopping of this deposit. Such repeated surges may become diluted and transform into hyperconcentrated flows (Pierson and Costa, 1987). A similar behaviour was also observed and described by Johnson (1970), for some debris flows at Wrightwood (California, USA) in 1969. In this case the front of the debris flow consisted of boulders, which gradually decreased is size in the body, until the debris flow became charged with pebble-sized fragments. This debris flow was then followed by material that seemed to have a lower percentage of pebbles. At the end the flow became more diluted until it turned to muddy water. Similar descriptions were given by Genevois et al. (2000), for some debris flows in the Dolomites (Italy). In this case the video recordings obtained from three measurement points showed that flow depth progressively decreased behind the surge front while an apparent decrease of sediment concentration also occurred, making the final tail look like a thin flow of muddy water. Recently Bianco and Franzi (2002) proposed an explanation of the alternation of different processes in time during the same debris flow event on the basis of a hydrological approach. 


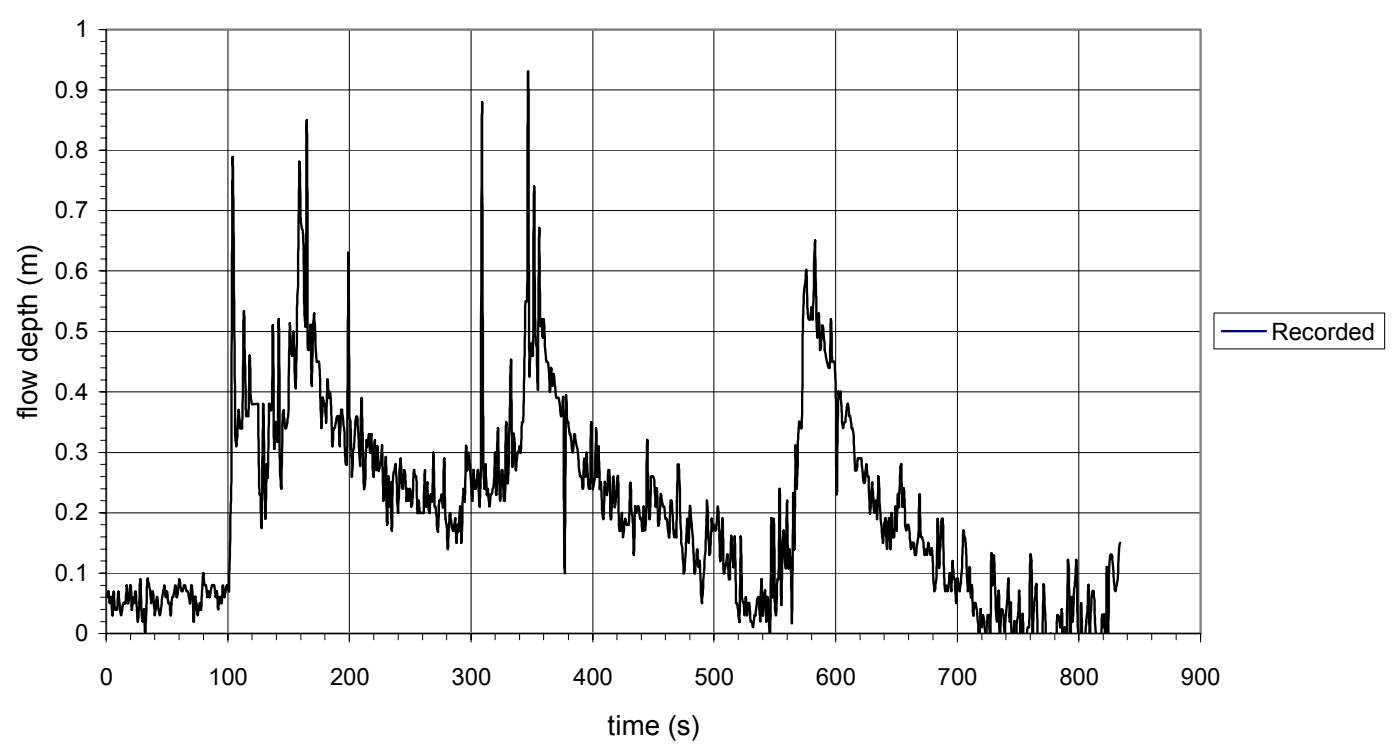

Fig. 1. Recorded hydrograph at the upstream sensor.

Different rheological behaviours have also been observed during the spreading of a debris flow on the fan. Because of the complex deposition and segregation process the separation of the debris material from the interstitial fluid (water or muddy fluid) may occur during propagation, in the torrent channel as well as during deposition on the debris fan. In this case (Shieh and Tsai, 1997), after entering the alluvial fan, the debris flow spreads out, reduces its momentum and then stops its movement after reaching a flatter area. The sediments segregate, deposit and leave a mud flood or simply clear water flowing downstream.

These observations show that during a storm an alternation of different types of phenomena may occur in time or in space in a torrent, ranging from debris flows to watersediment flows with intense bed load. A distinction between the different types of flows can be made by referring to a time scale similar to that of the flow event itself (Meunier, 1994). Following this approach debris flows appear to have a typical intermittent behaviour: a sequence of different surges throughout time often occur for the same event, whereas other events seem to show a steadier behaviour. Nevertheless, after a steady intense bed load has settled along a torrent, some spontaneous surges of water sediment flows may still occur and alter the continuous process of propagation through intense bed load. It follows that, for a given torrent, different physical processes may occur, during different rainfall events, and different dynamic characteristics can be shown during each of them.

Therefore, in water-sediment flow processes, different water-sediment flows may alternate in time, implying different sediment transport mechanics (Egashira and Ashida, 1992; Franzi and Bianco, 2000), different sediment concentrations (Franzi, 2002a), different resistance laws (Franzi and Bianco, 2003) and different dynamic characteristics. In this paper the application of a mathematical model and an empiri- cal resistance law to three water-sediment surges observed in an instrumented torrent (the Moscardo torrent) in 2002 will be discussed.

\section{Real case water-sediment flow chosen for the simula- tion}

The Moscardo torrent is a small torrent located on the Eastern Italian Alps that has been affected in the past by several debris flows (Marchi et al., 2002). It drains an overall area of about $4 \mathrm{~km}^{2}$ ranging in elevation from $890 \mathrm{~m}$ to $2043 \mathrm{~m}$.

In 1989 two ultrasonic sensors were placed on the fan of the torrent, where the bed slope is approximately $10 \%$ and the torrent reach is quite straight. In 1996 a third sensor was added upstream of the previously installed sensors and was maintained active until 1998. Nowadays only two ultrasonic sensors are installed along the torrent at a distance of $75 \mathrm{~m}$ from each other. The cross section width of the monitored torrent reach is about $8 \mathrm{~m}$. Considering the maximum flow heights of the debris flows observed in this torrent reach, ranging from few tens of $\mathrm{cm}$ to $2-3 \mathrm{~m}$ at most (Marchi et al., 2002), this cross section can be modelled as a broad rectangular section.

A flow event occurred on 4 August 2002 that was characterised by a first water-sediment surge, lasted about $120 \mathrm{~s}$, which preceded a second one, of about $100 \mathrm{~s}$. After an interval of about $150 \mathrm{~s}$, a third surge propagated along the torrent (Fig. 1).

The second hydrograph showed that the second and third surges did not change significantly their form, except for some variations in the third one, that, in the second hydrograph, appeared to have a more continuous variation of flow depth in the front and a lower gradient in the decreasing part. This form change can be theoretically predicted by means of a kinematic model (Arattano and Savage, 1994). 
No deposition or erosion could be detected along the channel reach between the gaging stations, due to the lack of an accurate torrent topographic survey before the event. Nevertheless the assumption of a non-erodible bed seems reasonable because no appreciable net change in bed elevation was observed in this event. The hypothesis can also be discussed and verified by means of the results obtained with the mathematical simulation.

\section{The mathematical model}

The mathematical model employed for the simulation assumes a homogeneous water-sediment flow over a rigid bed in unsteady conditions.

As mentioned above no deposition effects have been taken into account, implicitly assuming that no degradation or aggradation processes occurred along the channel. Due to the incised cross section shape and to the straight reach investigated, the propagation processes occurred during the event are assumed to be one-dimensional. Applying the mass and momentum conservation laws, a system of two partial differential equations is obtained and solved with an implicit finite-difference scheme:

$\frac{\partial Q}{\partial t}+g A \frac{\partial h}{\partial x} \cos (\theta)+\frac{\partial}{\partial x}\left(\frac{Q^{2}}{A}\right)+g A S_{f}-g A \tan (\theta)=0$

$\frac{\partial h}{\partial t}+\frac{1}{b} \frac{\partial Q}{\partial x}=0$

where:

$Q$ : water-sediment discharge;

A: area;

$b$ : free surface width;

$h$ : flow depth;

$\theta$ : bed slope angle;

$S_{f}$ : friction loss;

$x$ : downstream coordinate (positive downstream);

$g$ : gravity acceleration.

The rheological properties of the water sediment mixture must be specified to solve the system (1). The following closure equation has been used (Nsom et al., 1998; Rickenmann, 1999):

$S_{f}=\frac{U^{2}}{c^{2} h^{2 n}}$

where $c$ and $n$ are two parameters and $U$ is mean flow velocity.

Rickenmann (1999) finds that the best value for $n$ is $1 / 3$, according to the results of some numerical simulations of unsteady debris flow surges (Koch, 1998). Theoretical and laboratory investigations have been made by Takahashi (1991), who proposed $n=1.5$ for a dilatant flow behaviour (the dilatant flow behaviour applies for stony debris flows). Moreover, Takahashi (1991) found that the $c$ coefficient depends on the volume sediment concentration $C$, the interstitial fluid density and the mean grain size (Takahashi and Nakagawa,
1993). According to Rickenmann the $c$ coefficient depends also on the parameter $n$ and on the debris flow peak discharge (Rickenmann, 1999). Finally Coussot (1994) proposed the assumption of the Herschel-Bulkley model with $n=3$ to simulate muddy debris flows and mudflows.

It is noted that Eq. (2) neglects several factors that are known to characterize debris flow behavior. Because a yield stress term is not incorporated in Eq. (2) the model cannot account for the stopping of a debris flow. Furthermore Eq. (2) can be adequately employed to estimate the behavior of a water - sediment flow when the effects of friction (due to static interparticles contacts or to contacts between particles and the bed) are negligible with respect to the effects of interparticle collisions (Franzi and Bianco, 2000). Finally the effects due to the excess-pore fluid pressure (Hungr, 1995; Hutter et al., 1996; Iverson, 1997) are neglected in Eq. (2), which is possible only when the size of particles transported in the flow is quite coarse, with a very small fine fraction and with high drainage capability. This hypothesis is equivalent to stating that the excess pore pressure (if present) dissipates in time-scales much smaller then the time scale of the watersediment propagation.

It must be noticed that the existence of a yield stress would predict the presence of a rigid plug in the flowing mixture and a critical thickness for the flow, below which motion should stop and the debris flow should deposit. Previous researches in the Moscardo Torrent have shown that a rigid plug is not always observed for the debris flows in this torrent (Deganutti et al., 1998) while many of the hydrographs recorded so far show a descending limb that does not show any critical thickness below which a stop of the motion is observed (Marchi et al., 2002).

Equation (2) is often used in practice (Rickenmann, 1999) to describe the propagation phase of a debris flow in a channel, when the confinement produced by the torrent banks allows the maintenance of a high water content, as it occurs for the instrumented torrent reach here examined. The use of Eq. (2) for the sole simulation of the propagation phase of a debris flow is what will be investigated in this paper together with its capability to describe the behavior of the entire debris flow surge, from its frontal part to its tail. It is noted that Eq. (2) approximates the Herschel-Bulkley model or the Bingham model for small yield stress values.

In the mathematical simulation described above different values for $c$ and $n$ have been tested, in order to find the $[c, n]$ pair that allows to best fit the hydrograph of the considered debris flow event.

A steady flow has been assumed for the initial conditions, along the entire torrent reach; the solved equations are the same as those in system (1), except that the time-dependant terms are set to zero. This assumption does not affect the results, since the water-sediment discharges and flow depths (as well as their variation in time) are much larger than those of the initial water-sediment flow.

The upstream boundary conditions for $h$, that have been assumed in the simulation, are given by the upstream 


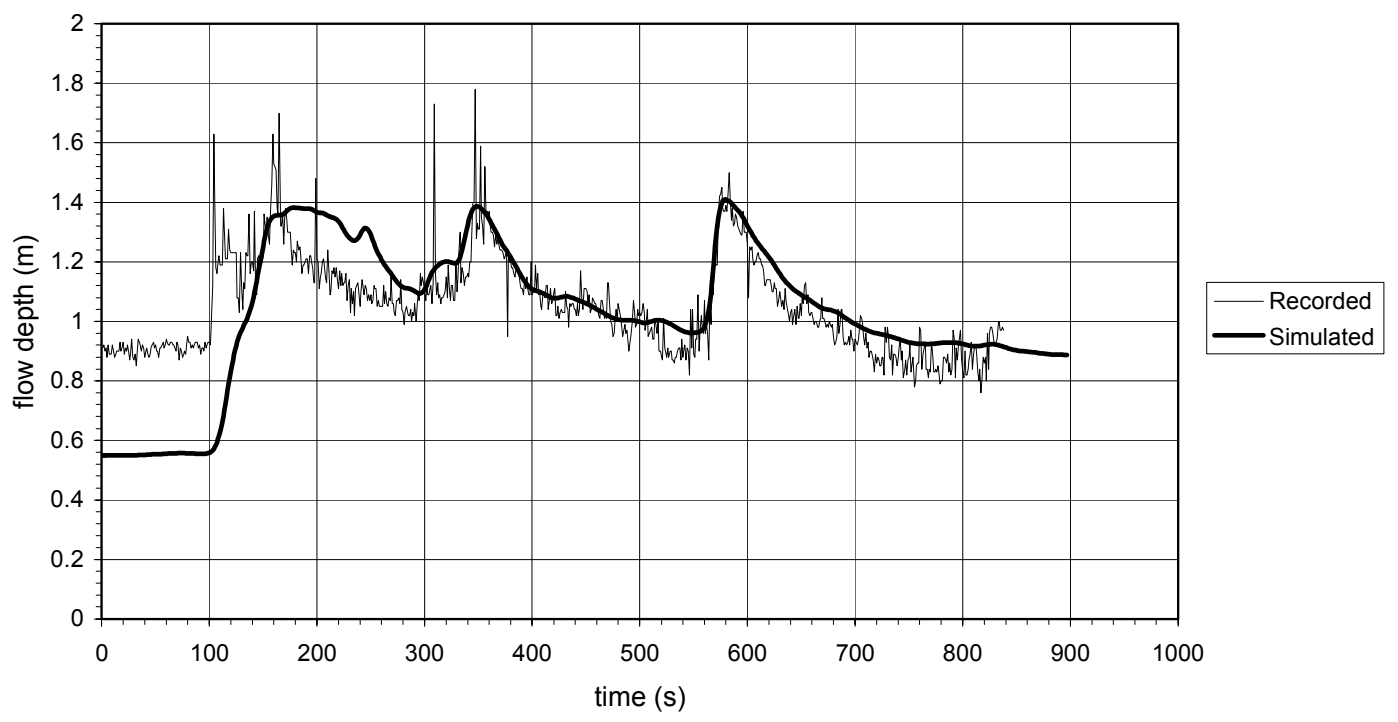

Fig. 2. Recorded and simulated hydrograph at the downstream sensor.

recorded hydrograph (Fig. 1). Therefore the boundary and initial conditions are the following:

$\left\{\begin{array}{l}t=0 \\ U=U(x) ; h=h(x) \text { for } 0<x<L ; \text { steadyflow }\end{array}\right.$

$\left\{\begin{array}{l}x=0 \\ U=f[h(0, t)] ; h=h(t) ; \text { for } 0 \leq t<\infty\end{array}\right.$

where $L$ is the length of the torrent reach, equal to the distance between the first and the second hydrograph $(75 \mathrm{~m})$. As indicated before, the $U(0, t)=f[h(0, t)]$ relationship in the upstream reach depends on the choice of the simulation parameters, according to Eq. (2). As the $h$ values are those recorded in the first hydrograph, the uncertainty in the estimation of $U$ (and consequently the uncertainty in the estimation of the debris flow discharge) is much smaller than that affecting other models, where both the upstream conditions, that is $h$ and $U$, have to be estimated (Honda and Egashira, 1997; Hirano et al., 1997). The assumption of uniform flow conditions in the upstream boundary can be found in other models (e.g. Hirano et al., 1997; Suzuky et al., 1993; Arattano and Savage, 1994 for kinematic models). For steep bed slopes, the assumption of uniform flow conditions can be the most reliable, because there is a predominance of the fourth and fifth term in the left side of the first equation of system (1) (Cunge, et al., 1980).

The simulations, performed for different $c$ and $n$ values maintaining the same boundary $h(0, t)$ and initial conditions, best fit the recorded hydrographs for the following values of the $[c, n]$ pair: $c=5 \mathrm{~m}^{0.7} / \mathrm{s}$ and $n=1.3$. The fit is fairly good. As far as the mathematical model is concerned, the results showed also that the momentum equation could be well approximated just by Eq. (2). For other $[c, n]$ values an under/over estimation of the water-sediment recorded hydrographs was obtained and a time-shift between the recorded and simulated hydrographs resulted (the simulated and recorded waves appeared shifted). The chosen $[c, n]$ pair minimises the mean square deviation.

As shown in Fig. 2, the simulated hydrograph fits fairly well the hydrograph recorded at the second gauging station. The simulation reproduces well all the three surges. The computed peak discharges of the first, second and third surges are $53.5 \mathrm{~m}^{3} / \mathrm{s}, 54 \mathrm{~m}^{3} / \mathrm{s}$ and $56 \mathrm{~m}^{3} / \mathrm{s}$, respectively.

The results allow a discussion of the hypothesis of no erosion and/or deposition along the torrent. By assuming, for the sake of simplicity, uniform flow conditions in correspondence to the upstream and downstream hydrographs, the velocities and total discharge can easily be computed for each computed flow depth. This allows computing the cumulated solid and liquid volumes flowing through the two cross sections, as it is represented in Fig. 3. The figure shows that, after the transition of the third water and sediment surge, the total volumes are almost the same.

\section{Comparison with other debris flows events}

As stated before, several debris flows occurred in the Moscardo torrent since 1989.

In particular the debris flows on 20 July 1993, 22 June 1996 and 8 July 1996 have been modelled (Arattano and Franzi, 2003) following the same procedure. In particular the 22 June 1996 event was characterised by four surges, the first of which showed flow depths up to $3.5 \mathrm{~m}$ high and a water sediment discharge around $170 \mathrm{~m}^{3} / \mathrm{s}$. The other surges were much smaller than the first one, with lower flow depths and flow discharges. The sediment transported by the flow was probably well sorted, with pebbles, cobbles and a huge stone, with a diameter of $2 \mathrm{~m}$. The peak discharge of the 20 July 1993 event was about $130 \mathrm{~m}^{3} / \mathrm{s}$, while the peak discharge of the 8 July 1996 event could not be confirmed by the 
Table 1. Comparison of the simulation parameters in the 1993, 1996 and 2002 Moscardo events. $\left(^{*}\right) c$ units depend on $n$ value, according to $[\mathrm{c}]=\mathrm{m}^{(1-n)} / \mathrm{s}$.

\begin{tabular}{ccccc}
\hline & 20 July 1993 & 22 June 1996 & 8 July 1996 & 4 August 2002 \\
\hline $\mathrm{c}\left({ }^{*}\right)$ & 14 & 14 & 14 & 5 \\
$n(-)$ & 0.2 & 0.2 & 0.66 & 1.3 \\
\hline
\end{tabular}

simulations, probably because of the partial deposition of the sediment along the reach, or the diversion of the flow itself with respect to the gauging station. As far as the simulation parameters, and the consequent rheological behaviours, are concerned, the obtained results (Table 1) were by far different from those here obtained.

The large variation in the value of $n$ from event to event shown in Table 1, suggests that the rheological coefficients are not general, even for the same torrent. This has implications both for science and engineering practice, particularly in applying rheological models to evaluate mitigation measures or to create hazard maps.

According to what we have previously mentioned about the different proposals made by researchers in literature, the values that have been found for the parameters of the model for the August 2002 event would account for a flow behaviour of the dilatant type, as that proposed by Takahashi (1978, 1980, 1991).

However a different interpretation can be given if the different resistance laws proposed in the literature are considered. It might be worth to discuss this different interpretation and this will be done in the following chapter.

\section{Discussion}

As we have previously mentioned several approaches have been adopted to study debris flows and many theories have been proposed in literature for the prediction of debris flows characteristics, based on observations made both in laboratory flumes or in natural torrents. On the other hand many resistance laws have been proposed in literature for water flows which, more in general, transport sediments. However only a few were obtained for water flows with intense solid transport occurring on steep slopes.

In particular, by analysing the experimental results of flume tests on sediment transport on steep slopes, Smart and Jaeggi (1983) obtained the following resistance to flow equation:

$$
\frac{U}{u_{*}}=2.5\left[1-\exp \left(-0.05 \frac{h}{d_{90} \cdot \tan \theta^{0.5}}\right)\right]^{0.5} \log \left(8.2 \frac{h}{d_{90}}\right)
$$

where $U$ is the mean flow velocity, $u_{*}$ is the shear velocity, $h$ the flow depth, $\theta \mathrm{g}$ the bed slope, and $d_{90}$ the grain diameter for which the $90 \%$ of sediment is smaller. The tests were performed with non uniform sediment $\left(1.3<d_{90} / d_{30}<8.4\right)$,

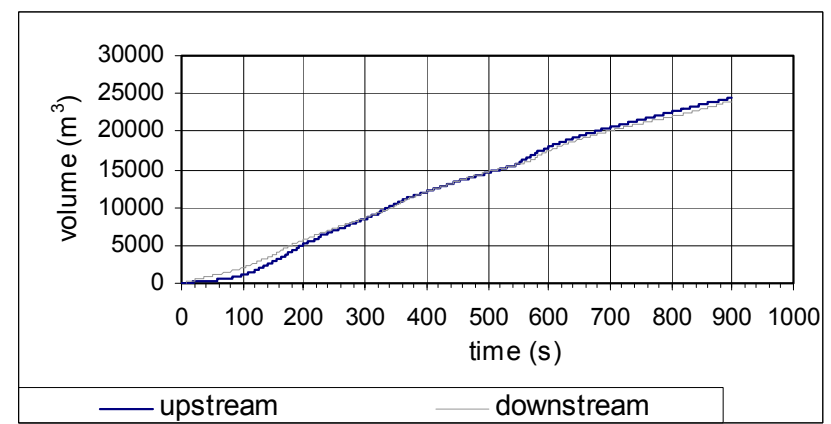

Fig. 3. Cumulated volume, at the upstream and downstream gauging station.

for $0.03<\tan \theta<0.20$, relative submergence $1.6<h / d<15.6$ and movable bed conditions. Actually the flume experiments performed by Smart and Jaeggi were used to propose a sediment transport equation, with a validity ranging from ordinary sediment transport to immature debris flows (Franzi, 2002b; Takahashi, 1987).

A simpler equation similar to Eq. (2) proposed by Rickenmann and Weber (2000) for natural torrents is also based on a relationship between $u / u_{*}$ and bed slope:

$\frac{U}{u_{*}}=\frac{0.69}{(\tan \theta)^{0.34}}\left(\frac{h}{d_{90}}\right)$

within the range $0.4<h / d_{90}<10$.

As either Eq. (5) or Eq. (6) are continuous functions, the resistance smoothly increases for steeper bed slope, for a given $h / d_{90}$.

For immature debris flows Takahashi (1991) proposed the following equation:

$\frac{U}{u_{*}}=k\left(\frac{h}{d}\right)$,

where $d$ is the mean diameter of the coarse fraction of the sediment. Takahashi (1991) set the coefficient $k$ equal to 0.4, while Nakagawa et al. (2000) set it equal to 0.7.

On the other hand, Takahashi (Takahashi, 1991; Nakagawa et al., 2000) proposed the following equation for debris flows:

$\frac{U}{u_{*}}=2 \sqrt{2}\left(C+(1-C) \frac{\rho}{\sigma}\right)^{1 / 2}\left[\left(\frac{C_{*}}{C}\right)^{1 / 3}-1\right]\left(\frac{h}{d_{90}}\right)$,

where $C_{*}$ is the maximum packing concentration, $C$ the sediment concentration inside the flow, $\rho$ and $\sigma$ the water and sediment densities, respectively.

According to these different approaches proposed to describe bed load transport on steep slopes and immature debris flows and according to previous experimental results obtained by simulating real case debris flows both in the Moscardo Torrent and in other catchments (Rickenmann, 1999) immature flows would be expected to show higher $n$ values than mature debris flows. Field evidences seem in fact to show that, for real case debris flows, $n$ tends to be 
quite small. As mentioned earlier, Rickenmann (1999) suggests the value of $1 / 3$ for $n$ and previous simulations of the Moscardo Torrent debris flows have found $n$ values as low as 0.2. Notice that the theoretical $n=0$ limit corresponds to the movement of a solid volume that does not flow and does not roll, but just translates as a rigid body. This apparent, nearly translation that sometimes occurs for debris flow and corresponds to very small values of $n$ (see Table 1 ) is produced by the fact that often debris flows possess a very fluid tail that flows at an higher velocity than that predicted for its flow height value by a single resistance law applied to the entire surge.

It is important to recall that for stony debris flow, according to Takahashi (1991) (Eq. 8) the value of $n$ should be higher and equal to 1.5.

The Moscardo field data recorded in 2002 are shown in Figs. 4 and 5.

A good match between the results computed by different Eqs. (5), (6), (7) has been obtained. In Fig. 4, Eqs. (5) and (6) are plotted for $d_{90}=0.4 \mathrm{~m}$. Takahashi's (1991) Eq. (7) is plotted for $d=d_{50}$, with the coefficient in the right term equal to 0.4 (Takahashi, 1991) and to 0.7 (Nakagawa et al., 2000). The $d_{50} / d_{90}$ ratio has been assumed to be $d_{50} / d_{90}=0.5$.

On the other hand, if Eq. (8) is plotted versus $h / d_{90}$ (Fig. 5), some hypotheses have to be made as far as the sediment concentration is concerned, that is the sediment flux as a percentage of the total water and sediment flow. To this aim, the equation proposed by Takahashi (1991) can be applied to compute the equilibrium solid concentration, that is:

$C=\frac{\rho \tan \theta}{(\sigma-\rho)(\tan \phi-\tan \theta)}$,

where $\phi$ is the internal friction angle. For $\phi=38^{\circ}$, it is $C=0.1$. As Eq. (9) refers to sediment equilibrium concentration in a flow over an infinite slope, it probably underestimates the concentration in the Moscardo reach that is here considered, that is in the downvalley river course, where the flow enters the debris fan with a higher solid concentration. Therefore a sensitivity analysis to $C$ can be tried, e.g. by assuming higher $C$ values. The results are shown in Fig. 5 where Eq. (9) is also plotted for two different $d_{90}$.

Figures (4) and (5) show that the resistance to flow for the Moscardo flow event in 2002 can be very well predicted by the Eqs. (5), (6), (7), (8) plotted in the figure. The resistance to flow equation proposed by Nakagawa et al. (2000) for immature debris flows, predicts well the simulated results too.

On one hand, as either Eqs. (5), (6) and (7) refer to watersediment flows, this can show that the behaviour of the Moscardo 2002 event can be assumed to be more similar to an immature debris flow than to a mature debris flow.

On the other hand, as also Eq. (8) well predicts the simulated results (for $C=0.3$ ), the rheological behaviour of the flow can also be considered to be similar to that of stony debris flows, as indicated by Takahashi (1991).

It must be noticed that the hydrograph form shown in Fig. 1 for the August 2002 event is typical of a mature debris flow, particularly its very steep front. A water flow with intense particle transport would have shown a smoother hydrograph. The results should be anyway confirmed by field observations on the total sediment concentration and mean diameter. As the best value for $n$ in the simulations was less than 1.5, this may indicate that the 2002 event showed dynamic characteristics between stony debris flows and immature debris flows.

The rheological behaviours of previous Moscardo's events (for which the rheological parameters $n$ were found to be by far less than that in 2002) were instead much more similar to that of a "rigid" translation, with higher flow depths and flow velocities. As indicated in Fig. 4, the velocities are higher, with respect to those ones observed in the 2002 event, and the proposed Eqs. (5), (6) and (7) under predict the dynamic behaviour of the flow.

\section{Field observations}

Figure 6 shows some of the deposits that were left by the event occurred on 4 August 2002 in the Moscardo Torrent.

These deposits appear to be quite coarse and with a very small fine fraction. These field evidences, together with the hydrograph form mentioned above would lead to interpret the debris flow occurred in the Moscardo Torrent on 4 August 2002 as a stony debris flow of little dimensions (just $50 \mathrm{~cm}$ of front height). Therefore the value of $n$ that results from the simulation must be considered as indicative of a dilatant flow behaviour as that proposed by Takahashi and not of an immature debris flow.

The considerations expressed in the previous chapter, however, still hold and account for the need of a field survey after each event in order to correctly interpret both the data monitored through the installed equipment and the results of the simulations. Different resistance laws may apply to different events for the same torrent, according to these evidences. Previous observations based on hydrographs recorded between 1990 and 1998 already showed that sometimes precursory surges are present before the arrival of the main front. This suggests a more fluid content of some of the Moscardo Torrent debris flows. Further field data, possibly including video observations, are needed to describe in greater detail the different types of flows, rheological behaviours and resistance laws existing in the Moscardo torrent.

\section{Conclusions}

Mechanical behaviour of a water-sediment flow may range from ordinary bed load to intense bed load to debris flows (either immature or mature or stony or muddy debris flows). As different mechanics may alternate in time during the same event, and inside the flow itself, the determination of the predominant rheological behaviour is not straightforward. Direct or videocamera observations may underpin theoretical evaluations, especially those obtained in laboratory experiments, but uncertainties may lay on the obtained results, due 

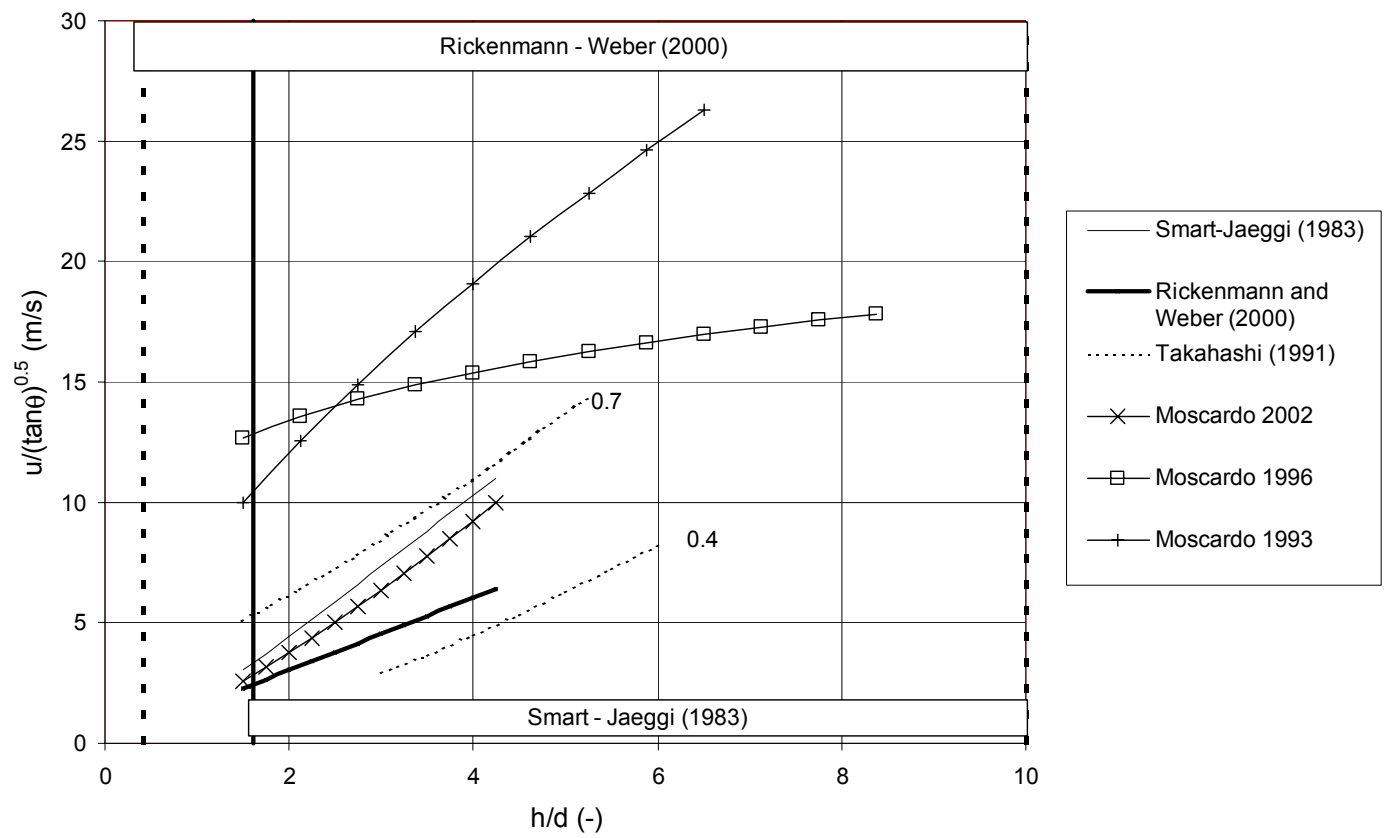

Fig. 4. Flow resistance equations for immature debris flows and comparison to simulation results. The range of validity of Smart and Jaeggi (1983) and Rickenmann and Weber (2000) equations are also indicated.

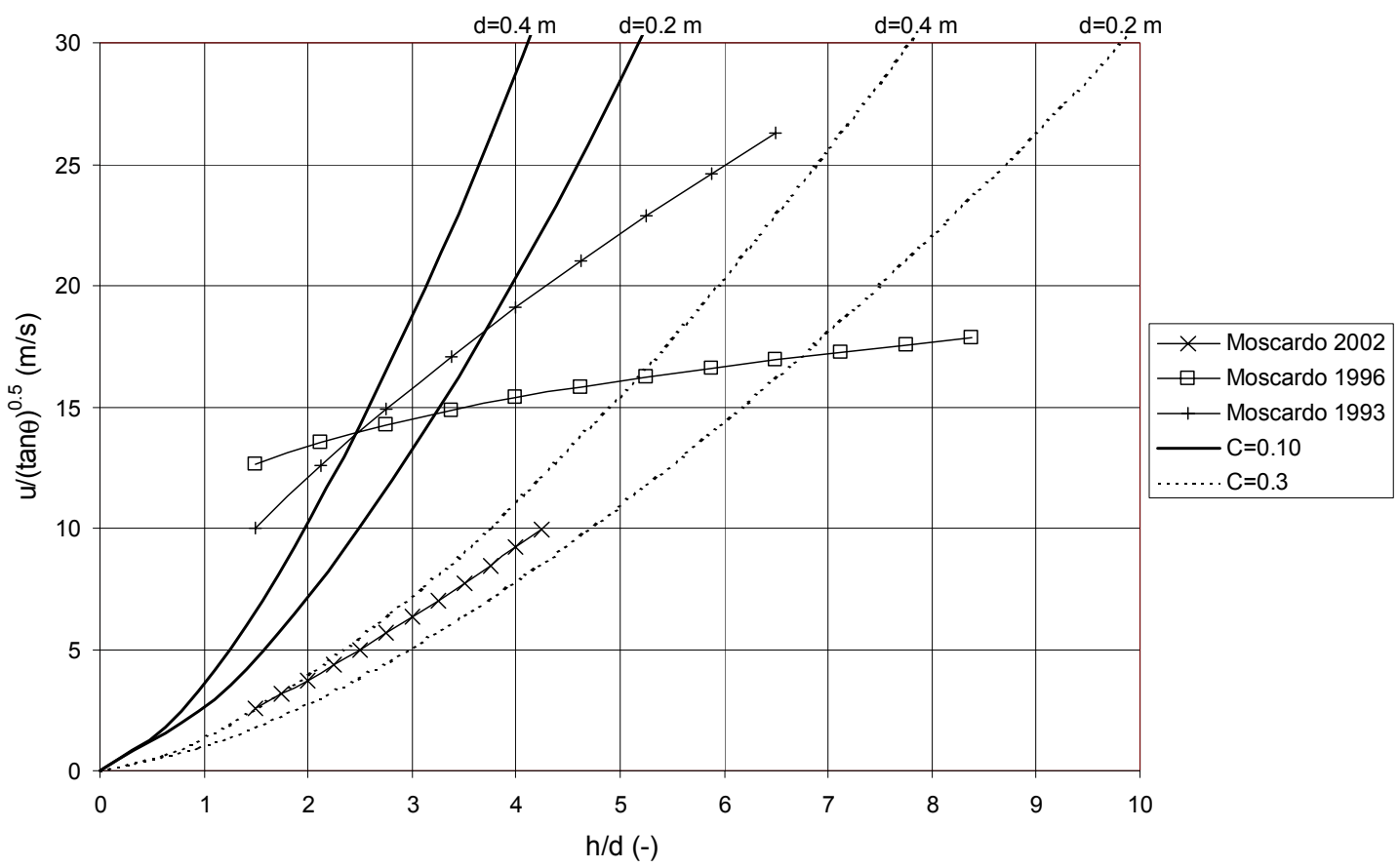

Fig. 5. Flow resistance equation for mature debris flows and comparison to simulation results.

to the lack of a complete understanding and of a monitoring of all the influencing factors (such as erosions, depositions, concentrations, tensional state and so on). Moreover several rheological behaviours may superpose during the same event or result to be intermediate between different extremes.

This has been evidenced in this paper by the calibration of a numerical model on the basis of some recordings ob- tained in the field through ultrasonic sensors. An empirical flow resistance law has been applied analyzing the values assumed by the parameters that appears in it. This has allowed to indirectly estimate the rheological behavior of a recorded debris flow that occurred in 2002 in an instrumented torrent (Moscardo Torrent, north-eastern Italian Alps). Parameter values of the flow resistance laws valid for solid transport in 


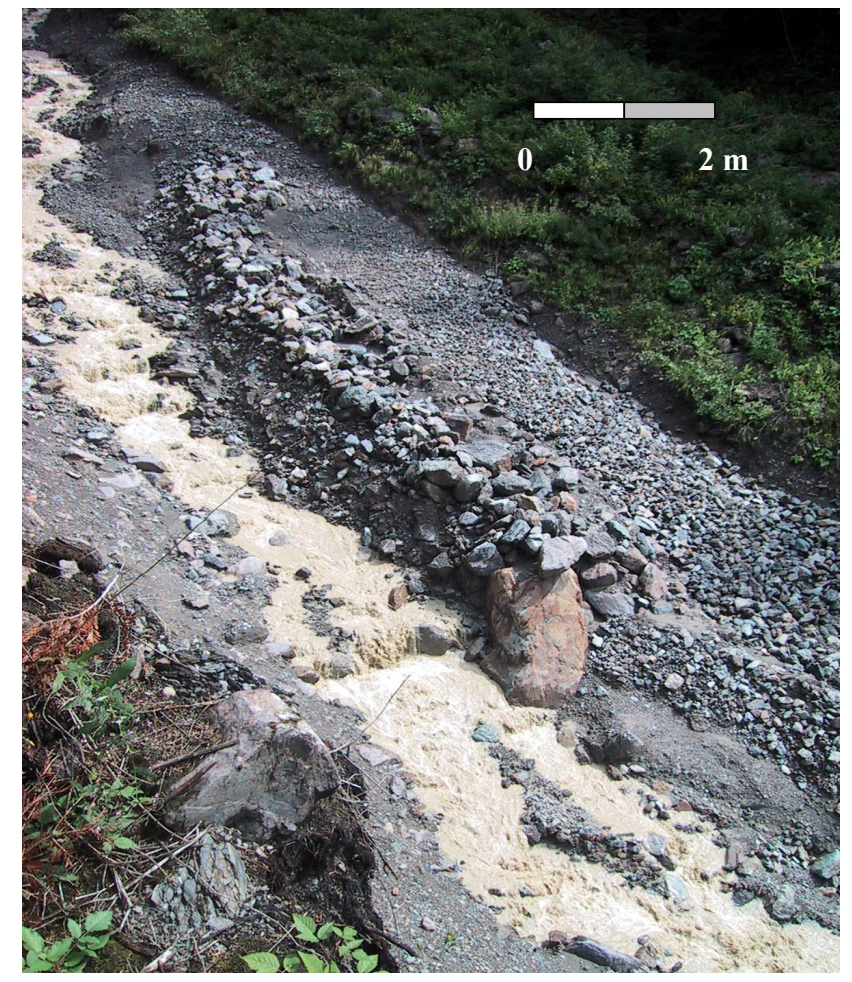

Fig. 6. Deposits left in the middle basin by the 4 August 2002 event in the Moscardo Torrent.

steep torrents and for immature debris flows allowed a good interpretation of the recorded data as well as parameters values valid for stony debris flows. Only the hydrograph form and the photos of some deposits left in the field by the event allowed to discriminate the type of flow that took place. The behaviour of the water sediment flow that occurred on $4 \mathrm{Au}-$ gust 2002 in the Moscardo Torrent should be considered a stony debris flow, with a rheological behaviour that is by far different from debris flows occurred in 1991, 1993, 1996 in the same torrent and previously modeled. Different resistance laws (and rheological behaviours) may apply to different events for the same torrent, according to these evidences. This has implications both for science and engineering practice, particularly in applying rheological models to evaluate mitigation measures or to create hazard maps.

Acknowledgements. The Forest Department of Friuli - Venezia Giulia Region is thanked for the collaboration in managing the field instrumentation.

Edited by: L. Marchi

Reviewed by: two referees

\section{References}

Arattano, M. and Franzi, L.: On the evaluation of debris flows dynamics by means of mathematicam models, Nat. Haz. Earth Sys. Sc., 3, 1-6, 2003.

Arattano, M. and Savage, W. Z.: Modelling debris flows as kinematic waves, Bulletin of the IAEG, 49, 95-105, 1994.
Bianco, G. and Franzi, L.: Condivisione dei metodi e conoscenze sui processi di lave torrentizie per la difesa dei centri abitati, Azione 4. Interreg II 1994-1999, Italy-Helvetic-Confederation, 63-78, 2002.

Coussot, P.: Rhéologie des laves torrentielles, La Houille Blanche, 3, 32-37, 1994.

Cunge, J. A., Holly Jr., F. M., and Verwey, A.: Practical aspect of computational River hydraulics, Pitman Publishing Limited, London, 1980.

Deganutti, A. M., Arattano, M., and Marchi, L.: Debris flows in the Mosscardo Torrent, I.R.P.I. Internal Report, 96/13 (video cassette), 1998.

Egashira, S. and Ashida, K.: Unified view of the mechanics of debris flows and bed load, Advances in Micromechanics of Granular Materials, Shen, Elsevier, 391-400, 1992.

Franzi, L. and Bianco, G.: The dispersive stresses range width as an indicator of debris-fows or bed load, Proceedings of the 2 nd International conference on debris flows hazard mitigation: mechanics, prediction and assessment, Taipei, 16-18 August, Rotterdam, Balkema, edited by: Wieczorek and Naeser, 351-359, 2000.

Franzi, L.: A simplified formula for the evaluation of water sediment currents concentration, Riverflow 2002, edited by: Bousmar and Zech, Swets \& Zeitlinger, Lisse, ISBN:9058095096, 963-968, 2002a.

Franzi, L.: On the variability of sediment concentration in currents on steep slopes: a simplified approach, J. Chem. Phys. Earth., 27/36, 1551-1556, 2002b.

Franzi L. and Bianco, G.: On the resistance to flow of debris flows and of water sediment currents with intense bed load, Proceedings International conference on Fast slope movements, prediction, and prevention for risk assessment, Naples, 227-233, 2003.

Genevois, R., Tecca, P.R., Berti, M., and Simoni, A.: Debris flows in the dolomites: experimental data from a monitoring system, Proceedings, 2nd International conference on debris flows hazard mitigation: mechanics, prediction and assessment, Taipei, 16-18 August, Rotterdam, Balkema, edited by: Wieczorek and Naeser, 283-291, 2000.

Hirano, M., Harada, T., Banuhabib, M. E., and Kawahara, K.: Estimation of hazard area due to debris flow, Proceedings of the 1st International ASCE Conference on Debris-Flow Hazard Mitigation: Mechanics, Prediction and Assessment, San Francisco, Ca, 7-9 August, 697-706, 1997.

Honda, N. and Egashira, S.: Prediction of debris flow characteristics in mountain torrents, Proceedings of the 1st International ASCE Conference on Debris-Flow Hazard Mitigation: Mechanics, Prediction and Assessment, San Francisco, Ca, 7-9 August, 707-716, 1997.

Hungr, O.: A model for the runout analysis of rapid flow slides, debris flows, and avalanches, Canadian Geotechnical Journal, 32, 610-623, 1995.

Hutter K., Svendsen B., and Rickenmann D.: Debris flow modeling: a review, Continuum Mech. Thermodyn., 1-35, 1996.

Iverson, R. M.: The physics of debris flows, Reviews of Geophysics, 35, 2, 245-296, 1997.

Johnson, A. M.: Physical processes in Geology, Freeman, Cooper and Co., 1970.

Koch, T.: Testing of various constitutive equations for debris flow modelling, Hydrology, Water Resources and Ecology in Headwaters, edited by: Kovar et al., IAHS, Publ. No. 248, Merano, Italy, 249-257, 1998. 
Marchi , L., Arattano, M., and Deganutti, A. M.: Ten years of debris flows monitoring in the Moscardo Torrent (Italian Alps), Geomorphology, 46, 1-17, 2002.

Meunier, M.: Les progrés de la connaissance et les méthodes d'études des phénomè torrentiels, La Houille Blanche, 3, 25-31, 1994.

Nakagawa, H., Takahashi, T., and Satofuka, Y.: A debris flow disaster on the fan of the Harihara River, Japan. Proceedings of the 2nd International conference on debris flows hazard mitigation: mechanics, prediction and assessment, Taipei, 16-18 August, Rotterdam, Balkema, edited by Wieczorek and Naeser, 193-201, 2000.

Nsom, B., Longo, S., Laigle, D., and Arattano, M.: Debris flow rheology and flow resistance, Thematic Report, U.E. contract Debris Flow Risk no. ENV4-CT96-0253, 49, 1998.

Pierson, T. C.: Flow behaviour of channelized debris flows, Mount S. Helens, Washington, in Hillslope processes, edited by: Abraham, A. D., Boston, Allen \& Unwin, 269-296, 1986.

Pierson, T. C. and Costa, J. E.: A rheological classification of subaerial sediment water flows, Geological Society of America, Reviews in Engineering Geology, 7, 1-12, 1987.

Rickenmann, D.: Empirical Relationship for debris flows, Natural Hazards, Kluver Academic Publisher, Printed in Netherlands, 47-77, 1999.
Rickenmann, D. and Weber, D.: Flow resistance of natural and experimental debris-flows in torrent channels, Proceedings of the 2nd International conference on debris flows hazard mitigation: mechanics, prediction and assessment, Taipei, 16-18 August, Rotterdam, Balkema, edited by: Wieczorek and Naeser, 245254,2000

Shieh, C. L. and Tsai, Y. F.: Experimental study on the configuration of debris flow fan. Proceedings of the 1st International conference on debris flows hazard mitigation: mechanics, prediction and assessment, Rotterdam, Balkema, 133-142, 1997.

Smart, G. and Jaeggi, M.: Sediment transport on steep slopes, Mitteilungen der Versuchsanstalt für Wasserbau, Hydrologie und Glaziologie, Zürich Nr. 64, 1983.

Suzuky, K., Watanabe, M., Kurihara, T., and Segawa, T.: Field study on debris and sediment flows in a small mountain torrent, Proceeding of the XXV IAHR Congress, Tokyo, 102-108, 1993.

Takahashi T. : Mechanical characteristics of Debris Flow, Journal Hydraulic Division, ASCE, 104, HY8, 1153-1169, 1978.

Takahashi T.: Debris Flow on prismatic open channel, Journal Hydraulic Division, ASCE, 106, HY3, 381-396, 1980.

Takahashi T.: High velocity flow in steep erodible channel, Proceedings 22th I.A.H.R. Congress, 42-53, 1987.

Takahashi, T.: Debris flows, Rotterdam, Balkema, 1991.

Takahashi, T. and Nakagawa, H.: Estimation of flood/debris flow caused by overtopping of a landslide dam, Proceedings of the XXV Congress of I.A.H.R., Tokyo, B, 117-124, 1993. 